05

Упрочнение поверхности

\title{
композиционного материала методом центробежного литья
}

\author{
(C) Е.Д. Эйдельман ${ }^{1,2}$, М.А. Дурнев ${ }^{1, \text { ฯ }}$ \\ ${ }^{1}$ Санкт-Петербургская государственная химико-фрармацевтическая \\ академия, Санкт-Петербург, Россия \\ ${ }^{2}$ Физико-технический институт им. А.Ф. Иоффре РАН, Санкт-Петербург, \\ Россия \\ ฯ E-mail: mad5245mail@gmail.com
}

Поступило в Редакцию 5 июня 2017 г.

На примере получения градиентного композитного материала алюминиевого сплава АК12 в смеси с базальтовыми волокнами изучено влияние течения вращения, возникающего при центробежном литье, на фазовый переход первого рода - кристаллизацию. Показана возможность получения материала с упрочненной поверхностью. Найдено распределение примесей в основном материале при наличии макроскопического движения.

DOI: 10.21883/PJTF.2018.07.45881.16902

Современное состояние исследований в области кристаллизации расплавов отражено в обзорах (см., например, [1]). В этой работе рассматривается заключительная стадия - развитие закритических зародышей [2, §99-102].

Реальная структура твердого состояния формируется именно на закритическом этапе кристаллизации. Этот этап (возможность получения заданного распределения основного и дополнительного материалов при центробежном литье) остается неизученным.

Без учета влияния течения спектр распределения закритических зародышей при фазовом переходе первого рода пар-жидкость вычислен в [3], а с учетом течения, создаваемого центростремительными силами и силой вязкого трения, действующими на частицы карбида бора, в [4].

В настоящей работе рассмотрено влияние течения при фазовом переходе первого рода жидкость-твердое тело, в частности созда- 


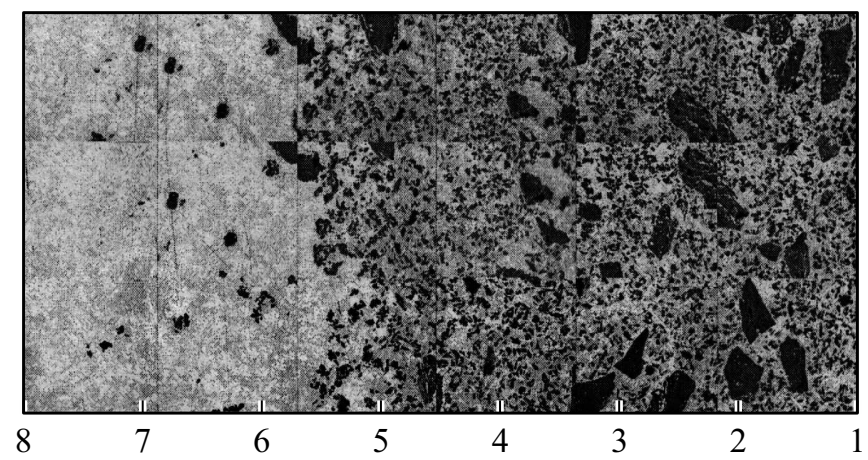

Рис. 1. Типичная микроструктура образца композита АК $12+5$ wt.\% базальта (темные области соответствуют базальту). Расстояния даны от наружной стенки образца (в $\mathrm{mm})$.

ваемого центростремительными силами, силой Архимеда и силой вязкого трения базальтовых частиц, именно на заключительной стадии кристаллизации, стадии коалесценции, когда рост крупных зародышей определяется поглощением мелких.

В качестве основного материала использовался алюминиевый сплав АК12, имеющий в жидком состоянии плотность $\rho_{a}=2.67 \mathrm{~g} / \mathrm{cm}^{3}$, а в качестве дополнительного - армирующие частицы базальта $\left(\rho_{b}=2.75 \mathrm{~g} / \mathrm{cm}^{3}\right)$. Состав образцов был следующим: АК $12+5 \mathrm{wt} . \%$ базальта (короткие волокна со средним диаметром $12 \mu \mathrm{m}$, длина $\leqslant 3 \mathrm{~mm}$ ).

Образцы изготавливались с применением технологии центробежного литья. Они имели форму цилиндров с наружным диаметром $2 r_{\text {max }} \approx 92-94 \mathrm{~mm}$, внутренним диаметром $2 r_{\text {min }} \sim 60 \mathrm{~mm}$, высотой 60-90 mm. Цилиндры разрезались на сектора по образующей, и анализировалась их боковая поверхность с наружной и внутренней сторон.

Режим центробежного литья был одинаков для всех образцов: температура нагрева оснастки $T=210 \pm 10^{\circ} \mathrm{C}$, температура расплава $T=750 \pm 10^{\circ} \mathrm{C}$, скорость вращения печи $n=1200 \mathrm{rpm}$, длительность обработки $3 \mathrm{~min}$.

Исследованы структура и распределение частиц в градиентных слоях на трех уровнях по высоте отливок. Исследования проводились на микроскопе Leica c использованием программного обеспечения. 


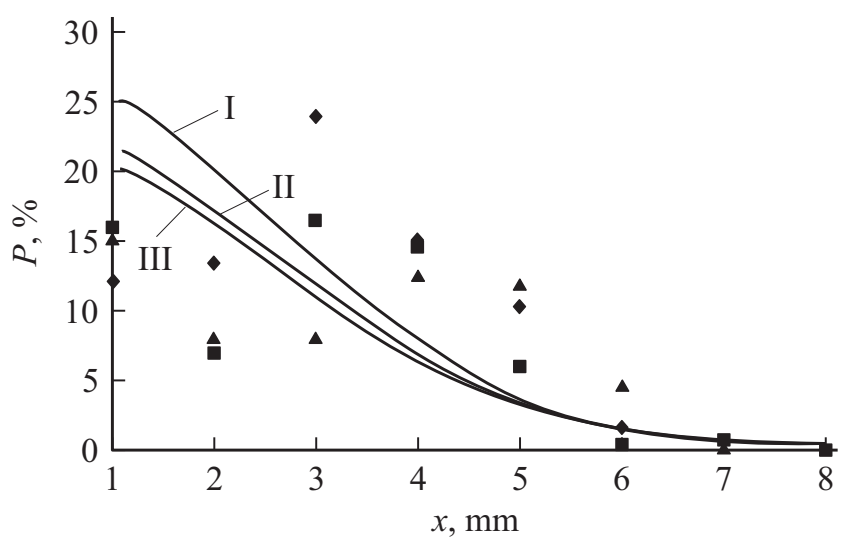

Рис. 2. Типичное распределение армирующих частиц в образцах композитного материала АК $12+5$ wt.\% базальта. I (ромбы), II (квадраты) и III (треугольники) - верх, середина и нижняя часть втулки соответственно. Сплошные линии - функции распределения.

Структура градиентных композиционных материалов показана на рис. 1, пересчет в распределение частиц базальта в градиентных слоях на трех уровнях по высоте отливок - на рис. 2.

Измерена твердость исследованных образцов. Измерения производились при помощи ультразвукового твердомера МЕТ-У1 (ТУ 4271001-18606393-00). Установлено, что введение базальтовых волокон повышает твердость АК12 в поверхностном слое в 1.2 раза.

Базальтовая частица объемом $V \approx 108 \pi \cdot 10^{-15} \mathrm{~m}^{3}$, погруженная в жидкий металл и вращающаяся вместе с ним с угловой скоростью $\omega=40 \pi \mathrm{rad} / \mathrm{s}$., находится под действием силы гидростатического давления, направленной к оси вращения и равной центробежной силе, развиваемой вытесненным объемом расплава. Подъемная сила, действующая на частицу, является равнодействующей элементарных подъемных сил и приложена в центре сил инерции вытесненного объема расплава. Поскольку плотности АК12 и базальтовых частиц практически одинаковы, можно считать, что $60<r \leqslant 92-94 \mathrm{~mm}-$ расстояние от центра инерции частицы до оси вращения - совпадает с расстоянием от центра инерции вытесненного жидкого АК12 до той же

Письма в ЖТФ, 2018, том 44, вып. 7 
оси. Тогда сила гидростатического давления запишется как

$$
F=\omega^{2} \operatorname{Vr}\left(\rho_{b}-\rho_{a}\right) .
$$

В соответствии с зависимостью (1) основная часть базальтовых частиц, находящихся во вращающемся расплаве, будет стремиться к перемещению в сторону внешних стенок образца - стенок изложницы. Превышение содержания базальтовых частиц у дна $\left(\rho_{b} \geqslant \rho_{a}\right)$ заметно только в области, на которую влияние стенки формы не распространяется. Можно предсказать, что при использовании армирующих частиц, имеющих плотность меньше, чем плотность основного металла, картина будет противоположной, и армирующие частицы будут собираться сверху.

Самой большой силой, действующей на базальтовую частицу и образующуюся вокруг нее область твердой фазы размером $R$, является сила вязкого трения $3 \pi \eta R v$, если базальтовая частица движется в расплаве со скоростью $v$. Если базальтовая частица свернута так, что твердую фазу вокруг нее можно считать шаром, имеющим плотность $\rho \approx \rho_{a} \approx \rho_{b}$, то сила будет в 2 раза больше. Коэффициент вязкости в жидком металле АК12 $\eta \approx 0.32 \mathrm{~Pa} \cdot \mathrm{s}$.

Легко найти, что начальная скорость $\omega r$ затухает со временем $t$ по закону

$$
v=\omega r \exp \left(-\frac{9 \eta}{4 \rho R^{2}} t\right) .
$$

Именно скорость (2) заменяет среднеквадратичную скорость движения малых зародышей, которые поглощаются - соединяются с большими - при отсутствии течения. За время, меньшее, чем характерное время затухания $\sim 30 \mathrm{~ms}$, именно эта скорость определяет вероятность поглощения большим $(R \approx 3 \mathrm{~mm})$ зародышем малых.

В [3] приведена функция распределения зародышей по размерам в условиях отсутствия движения, не учитывающая распределение по пространству [5]:

$$
G \approx \frac{1}{\sqrt{D t}} \exp \left[-\frac{\left(d-d_{0}\right)^{2}}{4 D t}\right] .
$$

Степень закритичности определяет отклонение размера зародыша $d$ от критического размера $d_{0}$. При наличии движения [4] вместо коэффици- 
ента диффузии нужно подставлять в (3) величину

$$
D=C \omega r R \exp \left(-\frac{9 \eta}{4 \rho_{a} R^{2}} t\right)
$$

где $C$ - постоянная порядка единицы.

В условиях коалесценции, которые имеют место перед кристаллизацией, размер $d \gg d_{0}$ и определяется диаметром базальтового волокна. Именно сечения базальтовых волокон и видны на рис. 1 (темные области). Можно считать, что базальтовые волокна являются зародышами. При сильном вращении центробежные силы способствуют росту преимущественно в направлении от оси вращения к изложнице. Отсюда следует, что размер зародыша $d$ становится равным расстоянию от первоначального положения зародыша до внешней границы расплава.

Для получения из выражения (3) распределения $P$ базальтовых волокон - армирующей примеси в образце - в него нужно подставить время фазового перехода $t_{f}$, которое гораздо меньше характерного времени затухания $4 \rho_{a} R^{2} /(9 \eta)$, и величину $D$, которая определяется течением в соответствии с формулой (4).

Запишем распределение (содержание) закритических зародышей базальтовых волокон - перед фазовым переходом в зависимости от расстояния $x$, отсчитанного от внешней стенки образца или, что то же самое, от изложницы. Имеем

$$
P(x)=A \exp \left(-\frac{x^{2}}{4 \sigma^{2}}\right) .
$$

Здесь $A-$ амплитуда, которая имеет вид

$$
A=\frac{B}{\sqrt{\omega r R t_{f}}} \exp \left(-\frac{9 \eta}{8 \rho R^{2}} t_{f}\right) .
$$

Эта величина включает параметр $B$, зависящий от сил плавучести.

Среднеквадратичное отклонение в распределении

$$
\sigma=\sqrt{\omega r R t_{f}} \exp \left(-\frac{9 \eta}{8 \rho R^{2}} t_{f}\right)
$$

можно считать не зависящим от архимедовой силы. Величина $C$ из (4) включена в величину $t_{f}$, определенную наиболее грубо.

Письма в ЖТФ, 2018, том 44, вып. 7 
Расчетные кривые распределений зародышей - базальтовых волокон - по $x$, отсчитанные от наружной стенки при отвердевании расплава, представлены на рис. 2 сплошными линиями.

Для определения параметров кристаллизации - фазового перехода первого рода - были обработаны экспериментальные данные. Сплошные линии на рис. 2 построены по формулам, имеющим вид (5), при условии минимума среднеквадратичного отклонения от экспериментальных значений. Основная часть погрешности обусловлена тем, что армирующие базальтовые частицы имеют форму нитейцилиндров, причем размер нитей того же порядка, что и размер области кристаллизации.

Кривые имеют следующие параметры: линия I, соответствующая верхней части образца, характеризуется амплитудой $27.6 \%$ и величиной $4 \sigma^{2}$, входящей в знаменатель показателя экспоненты, $13.0 \mathrm{~mm}^{2}$; линия II, отвечающая средней части, имеет параметры $23.5 \%$ и $13.2 \mathrm{~mm}^{2}$; линия III (для нижней части) - параметры $22.5 \%$ и $13.1 \mathrm{~mm}^{2}$. Как видно из рис. 1, армирующие частицы распределены между частями II (середина) и III (низ) образца равномерно, поэтому соответствующие линии на рис. 2 слабо различаются между собой. Для упрощения эти две линии будут рассматриваться как одна с параметрами $A=24 \%$ и $\sigma=1.8 \mathrm{~mm}$.

Распределения, представленные на рис. 2, наилучшим образом совпадают с экспериментальными результатами, полученными в результате обработки непосредственных наблюдений по рис. 1, если размер зародыша достигает размера области кристаллизации, равного примерно $R \approx 6 \mathrm{~mm}$ (рис. 1 ), за время в $1-2 \mathrm{~ms}$. Это и есть оценка времени фазового перехода первого рода - кристаллизации в расплаве композита АК12 с армирующими базальтовыми частицами-нитями. Теперь из (6) можно легко определить параметр $B$, зависящий от сил плавучести: $B=2.7 \mathrm{~mm}$.

Измерения твердости образцов показали, что методом центробежного литья можно изготавливать градиентные композиционные материалы с твердым поверхностным слоем, обладающим повышенной износостойкостью.

Впервые найдено конкретное распределение закритических зародышей при учете наличия макроскопического движения - вращения. Это позволяет надеяться на то, что движение расплава будет инструментом конструирования материалов с новыми свойствами.

Письма в ЖТФ, 2018, том 44, вып. 7 
Авторы признательны М.Л. Хейфецу, который привлек их внимание к исследованию центробежного литья, а также благодарят Ю.С. Алексееву за помощь.

\section{Список литературы}

[1] Кукушкин С.А., Осипов А.В. // Кинетика и катализ. 2008. Т. 49. № 1. С. 85-98.

[2] Лифиии Е.М., Питаевский Л.П. Физическая кинетика. М.: Физматлит, 2004. $536 \mathrm{c}$.

[3] Курасов В.Г. // Письма в ЖТФ. 2015. Т. 41. В. 7. С. 89-95.

[4] Durnev M.A., Eidelman E.D. // Nanosystems: physics, chemistry, mathematics. 2017. V. 8. N 3. P. 360-364.

[5] Кукушкин С.А., Григорьев Д.А., Индейцев Д.А., Потапов О.В., Фокин В.М. // Физика и химия стекла. 2001. Т. 27. № 3. С. 377-389.

Письма в ЖТФ, 2018, том 44, вып. 7 